In conclusion, we acknowledge the limitations of research in this complex subgroup with chronic heroin addiction and also the evidence of benefit from oral methadone in the broader population of people addicted to the drug. However, we consider the important findings reported in the paper are that, for this subgroup doing persistently badly on oral methadone treatment, it is important for clinicians to work with their patients to explore alternative options, such as injectable treatments, which may achieve health benefits not being achieved in the expected manner with the orthodox first-line treatment, and which may achieve this health benefit in a more cost-effective manner. Such personalisation of treatment plans is important but is currently being hindered by the cost implications of providing injectable alternatives and a previous lack of evidence of cost-effectiveness.

1 Byford S, Barrett B, Metrebian N, Groshkova T, Cary M, Charles V, et al. Cost-effectiveness of injectable opioid treatment $v$. oral methadone for chronic heroin addiction. Br J Psychiatry 2013; 203: 341-9.

2 Strang J, Metrebian N, Lintzeris N, Potts L, Carnwath T, Mayet S, et al. Supervised injectable heroin or injectable methadone versus optimized oral methadone as treatment for chronic heroin addicts in England after persistent failure in orthodox treatment (RIOTT): a randomized trial. Lancet 2010; 375: 1885-95.

3 National Institute for Health and Clinical Excellence. Methadone and Buprenorphine for the Management of Opioid Dependence (NICE Technology Appraisal TA114). NICE, 2007

4 Strang J, Babor T, Caulkins J, Fischer B, Foxcroft D, Humphreys K. Drug policy and the public good: evidence for effective interventions. Lancet 2012; 379 71-83.

5 Groshkova T, Metrebian N, Hallam C, Charles V, Martin A, Forzisi L, et al. Treatment expectations and satisfaction of treatment-refractory opioiddependent patients in RIOTT, the Randomised Injectable Opiate Treatment Trial, the UK's first supervised injectable maintenance clinics. Drug Alcohol Rev 2013; 32: 566-73.

Sarah Byford, Centre for the Economics of Mental and Physical Health, Box P024 Institute of Psychiatry, De Crespigny Park, London SE5 8AF, UK. Email: s.byford@kcl.ac.uk; Barbara Barrett, Centre for the Economics of Mental and Physical Health, Nicola Metrebian, Addictions Department, National Addiction Centre, Institute of Psychiatry King's College London, UK' Teodora GroshkOVa, Centre, Institute of Psychiatry, King's College London, Uk, Teodora Groshkova, European Monitoring Centre for Drugs and Drug Addiction, Lisbon, Portugal; Maria Cary, Centre for the Economics of Mental and Physical Health, Vikki Charles, Addictions Department, National Addiction Centre, Institute of Psychiatry, King's College London, UK; Nicholas Lintzeris, The Langton Centre, South Eastern Sydney Local Health District, NSW Health, Australia; John Strang, Addictions Department, National Addiction Centre, Institute of Psychiatry, King's College London, UK

doi: 10.1192/bjp.204.3.241a

\section{Psychosis as a failure of reality testing}

Garety \& Freeman present a timely review on the nature of delusional experience. ${ }^{1}$ Their conclusion regarding the need to focus on individual features of psychosis seems apt. The presented overview of cognitive and affective mechanisms influencing delusion development seems, however, to overlook an essential component of delusional experience; that psychotic symptoms, including delusions, at their heart represent a failure of reality testing.

The description of jumping to conclusions, together with the probabilistic reasoning task methodology, appear to rely on a logical chain of thought progression and conclusion - what Campbell has referred to as an empiricist understanding. ${ }^{2}$ This approach, however, does not take into account the nature of conclusions reached in delusional belief. Conclusions reached on seeing two, or fewer, coloured counters seem quite distinct from classic examples of delusional perception: 'I saw the traffic lights turn green and realised that the world would end'. Campbell's alternative rationalist approach presents the person with delusions as having experienced a complete rearrangement of their framework propositions, or underlying background world beliefs.
Such a fundamental shift in a world-view model can go some way to explaining the fantastical nature of conclusions reached, or the failure of reality testing present in psychosis.

Campbell's arguments have not gone unchallenged. ${ }^{3}$ However, what they do highlight is a need for careful consideration as to the manner in which delusional beliefs are formed. Garety \& Freeman describe the psychoanalytic thinking in relation to defence mechanisms in the development of persecutory delusional belief. Psychotic defence concepts, wherein the individual denies or distorts reality to defend against trauma, provide one possible lens through which psychotic experiences can be viewed. ${ }^{4,5}$

Garety \& Freeman's conclusion relating to the infancy of research into the nature of delusion, and its having been overshadowed by focus on the larger concept of schizophrenia, highlights the need for further research. Future research will need to provide some account for the distortion of reality that seems central to the experience of psychosis.

1 Garety PA, Freeman D. The past and future of delusions research: from the inexplicable to the treatable. Br J Psychiatry 2013; 203: 327-33.

2 Campbell J. Rationality, meaning, and the analysis of delusion. Philos Psychiatr Psychol 2001; 8: 89-100.

3 Bayne T, Pacherie E. Bottom-up or top-down: Campbell's rationalist account of monothematic delusions. Philos Psychiatr Psychol 2004; 11: 1-11.

4 Hingley SM. Psychodynamic perspectives on psychosis and psychotherapy. I: Theory. Br J Med Psychol 1997; 70: 301-12.

5 Martindale B, Summers A. The psychodynamics of psychosis. Adv Psychiatr Treat 2013; 19: 124-31.

Andrew Shepherd, Doctor, University of Manchester, UK Email: andrew.shepherd3@nhs.net

doi: 10.1192/bjp.204.3.242

Authors' reply: We differ in our approach from that taken by Shepherd, in that we are advocating an empirical approach which posits hypotheses that can be and are tested. Our review of over 200 studies demonstrates how much has been learned by testing hypotheses, amassing evidence and replicating findings. ${ }^{1}$ Thus there is now strong and consistent evidence that delusions are associated with biases in reasoning, such as are assessed by experimental tasks and reliable interviews. These findings are important and provide an explanation of the failure to take on board all the evidence - or a failure of reality testing, as Shepherd puts it. We now therefore have secure knowledge of specific reasoning processes which may be targeted in treatment. ${ }^{2}$

We do not agree that world beliefs are fundamentally rearranged in people with delusions. Rather, the person's delusions can be shown to build on the pre-existing thoughts about self and world, and are actually typically preceded by periods of anxious worry. ${ }^{3}$ Traditional views of sudden dramatic changes are not in general supported by the evidence. Although we show that there is clear evidence of the importance of emotional processes - and in some cases this can be linked to childhood trauma - we do not conclude that the delusion represents a defence. The psychoanalytic defence accounts are not supported by the evidence. Rather, anxiety and depression - and negative views of self and others - are risk factors for and commonly expressed by patients with delusions. ${ }^{4}$ We consider that these research findings render delusions explicable, and may have implications for the way all clinicians engage with people with delusions.

We advocate that there is now enough certainty in the evidence base for concerted efforts to translate them into targeted treatments for delusions. It is through further trials, drawing on the evidence base which identifies mechanisms underpinning 